\title{
Study on Modeling and Simulation Technology of Comprehensive Passenger Hub System
}

\author{
Yingying $\mathrm{Su}^{1, \mathrm{a}}$, Lisheng $\mathrm{Qu}^{1, \mathrm{~b}}$ and Mengling Huang ${ }^{1, \mathrm{c}}$ \\ ${ }^{1}$ School of Mechanical Engineering, Shenyang University, Liaoning, Shenyang, 110044, China; \\ asyyle2012@163.com, b1518271662@qq.com, '569833346@qq.com
}

Keywords: modeling and simulation, comprehensive passenger hub system, scheduling time, inventory time.

\begin{abstract}
Giving priority to the development of urban public transport is not only an effective measure to alleviate urban traffic congestion, but an inevitable requirement for improving urban livingenvironment and promoting the sustainable development of cities. System simulation of scheduling time and inventory time for comprehensive passenger hub system of Shenyang North Railway Station by using object oriented discrete modeling and simulation theory are studied to meeting passengers' demand and improve the efficiency of the public transportation system. Transportation simulation platform is built by using computer simulation and the station simulation model is set up, which are to find out the bottleneck of the whole system and formulate adjustment and optimization scheme, providing a feasible solutionfor the bus company bus scheduling decision.
\end{abstract}

\section{Introduction}

Traffic has an important role in urban development. With the improvement of China's urban economic development and urbanization, traffic congestion has become a major problem restricting China's economic and social development ${ }^{[1]}$. The bus priority strategies are proposed in most cities of our country. However, for comprehensive passenger hub system, bus scheduling research is still in its infancy. At present, there is nonsystematic approach and mature theory to fit for the situation of our country transportation hub station scheduling, data statistics and analysis. Simulation method is used and simulation model is established for Comprehensive Passenger Hub System of Shenyang North Railway Station, according to the scheduling ${ }^{[2-3]}$ and inventory, combined with different bus scheduling strategy, determines the appropriate grid frequency to achieve both bus corporate profits and passenger service quality, which provides the basis for transit operator to make departure plans.

\section{Key Technologies of modeling}

Queueing Model. Customers start from customer source and arrive at services (service desk, the waiter), and wait in a queue to receive services according to the rules of the queue in general queuing process. Services serve for customers according to the rules of the service. Customers receive services and then left. The general model of queuing system is shown in Fig. 1. Among them, the distribution of the interval of customer arrival, the type of service time and the parameters are the basic data of the queuing system model. Common theoretical distribution forms in queuing system model include deterministic distribution (D), the Markov distribution (M), normal distribution, $\operatorname{Erlang}\left(E_{k}\right)$ and uniform distribution.

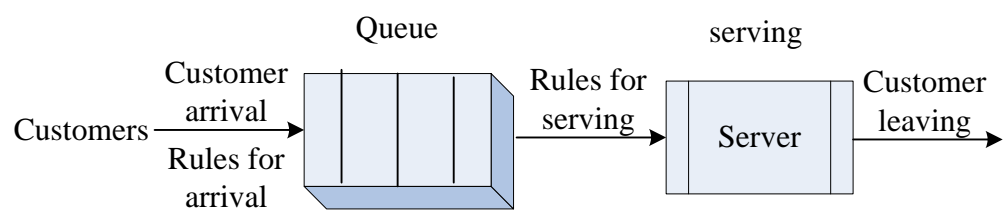

Fig. 1 The general model of queuing system 
Inventory model. Inventory is the process between supplementary and demand. Supplementary process includes ordering, production, transportation and other activities increasinginventory. And demand process describes use, sale and inventory costs and a variety of activities decreasing inventory. The general model of inventory system is shown in Fig. 2.

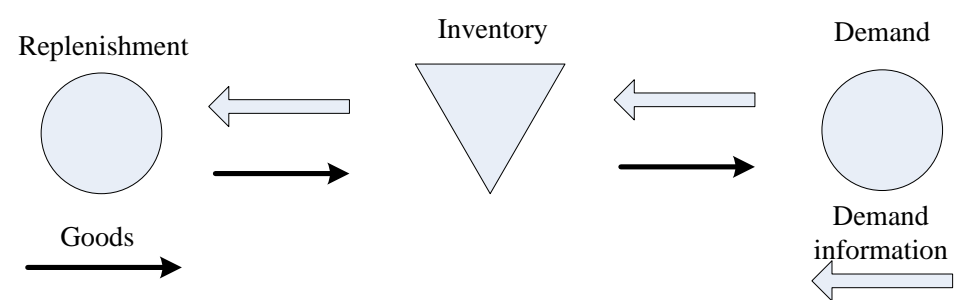

Fig. 2 The general model of inventory system

The information (including demand information, order information, etc.) and the delivery of materials (inventory materials) are described by the arrow. The virtual arrow indicates the information transmission, and the real arrow indicates the delivery of goods and materials.

\section{Research Data}

Scheduling analysis of No.224. The analysis of departure interval (scheduling) of No.224 is shown in Table 1.

Table 1 Departure interval time of No.224

\begin{tabular}{c|c|c|c|c|c|c|c}
\hline Time & $9: 30 \sim 10: 00$ & $\begin{array}{c}10: 00 \sim 10: 3 \\
0\end{array}$ & $\begin{array}{c}10: 30 \sim 11: 0 \\
0\end{array}$ & $\begin{array}{c}11: 00 \sim 11: 3 \\
0\end{array}$ & $\begin{array}{c}11: 30 \sim 12: 0 \\
0\end{array}$ & $\begin{array}{c}13: 00 \sim 13: 3 \\
0\end{array}$ & $\begin{array}{c}13: 30 \sim 14: 0 \\
0\end{array}$ \\
\hline $\begin{array}{c}\text { Average } \\
\text { interval } \\
\text { time }\end{array}$ & 9.3 & 6.8 & 7 & 7 & 6.5 & 6.6 & 6 \\
\hline Time & $\begin{array}{c}14: 00 \sim 14: 3 \\
0\end{array}$ & $\begin{array}{c}14: 30 \sim 15: 0 \\
0\end{array}$ & $\begin{array}{c}15: 00 \sim 15: 3 \\
0\end{array}$ & $\begin{array}{c}15: 30 \sim 16: 0 \\
0\end{array}$ & $\begin{array}{c}16: 00 \sim 16: 3 \\
0\end{array}$ & $\begin{array}{c}16: 30 \sim 17: 0 \\
0\end{array}$ & \\
\hline $\begin{array}{c}\text { Average } \\
\text { interval } \\
\text { time }\end{array}$ & 7 & 6.6 & 5.6 & 6.8 & 7 & 7.3 & \\
\hline
\end{tabular}

According to the data obtained from the table, three times standard deviation method is used to remove outliers, as shown in formula (1) and (2).

$$
\bar{X}=\frac{\sum_{i=1}^{n} X_{i}}{n}=6.9 \quad \sigma=\sqrt{\frac{\sum_{i=1}^{n}\left(X_{i}-\bar{X}\right)^{2}}{n}}=0.8
$$

Upper Control Limit $=\bar{X}+3 \sigma=9.3$

Lower Control Limit $=\bar{X}-3 \sigma=4.5$

Statistical data are without outliers. Graphics are made in Fig. 3 and the fitting are carried out.

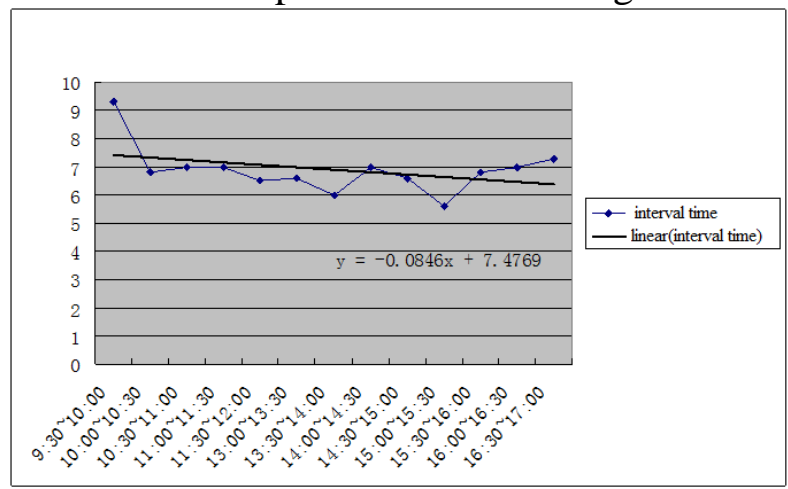

Fig.3 Data fitting of departure interval time for No.224 
The departure interval of No.224 showed a linear trend from Fig. 3. It fluctuates in the straight line of $7 \mathrm{~min}$, which indicates that the scheduling of No.224 bus on the weekend is once every seven minutes. And time scheduling is fixed evenly.

Analysis of population flow of No.224 bus station. Analysis of population flow of No.224 bus station is shown in Table 2.

Table 2 Numbers of passengers of No.224 bus station

\begin{tabular}{c|c|c|c|c|c|c|c}
\hline Time & $9: 30 \sim 10: 00$ & $\begin{array}{c}10: 00 \sim 10: 3 \\
0\end{array}$ & $\begin{array}{c}10: 30 \sim 11: 0 \\
0\end{array}$ & $\begin{array}{c}11: 00 \sim 11: 3 \\
0\end{array}$ & $\begin{array}{c}11: 30 \sim 12: 0 \\
0\end{array}$ & $\begin{array}{c}13: 00 \sim 13: 3 \\
0\end{array}$ & $\begin{array}{c}13: 30 \sim 14: 0 \\
0\end{array}$ \\
\hline $\begin{array}{c}\text { Numbers of } \\
\text { passengers }\end{array}$ & 19 & 19 & 21 & 29 & 26 & 24 & 30 \\
\hline Time & $\begin{array}{c}14: 00 \sim 14: 3 \\
0\end{array}$ & $\begin{array}{c}14: 30 \sim 15: 0 \\
0\end{array}$ & $\begin{array}{c}15: 00 \sim 15: 3 \\
0\end{array}$ & $\begin{array}{c}15: 30 \sim 16: 0 \\
0\end{array}$ & $\begin{array}{c}16: 00 \sim 16: 3 \\
0\end{array}$ & $\begin{array}{c}16: 30 \sim 17: 0 \\
0\end{array}$ & \\
\hline $\begin{array}{c}\text { Numbers of } \\
\text { passengers }\end{array}$ & 46 & 36 & 30 & 42 & 36 & 45 & \\
\hline
\end{tabular}

According to the data obtained from the table, three times standard deviation method is used to remove outliers, as shown in formula (3) and (4).

$$
\bar{X}=\frac{\sum_{i=1}^{n} X_{i}}{n}=31 \quad \sigma=\sqrt{\frac{\sum_{i=1}^{n}\left(X_{i}-\bar{X}\right)^{2}}{n}}=9.4
$$

Upper Control Limit $=\bar{X}+3 \sigma=58$

Lower Control Limit $=\bar{X}-3 \sigma=4$

The statistical data are without outliers. Graphics are made Fig. 4 and the fitting are carried out.

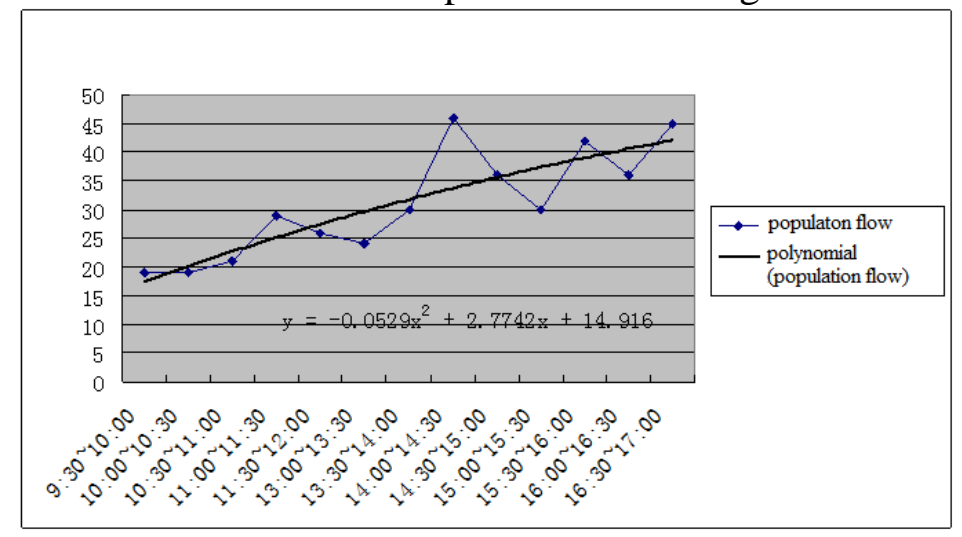

Fig.4 Data fitting of population flow for No.224 bus station

Population flow of No.224 bus station on the weekend over time is a normal distribution of $\mathrm{X} \sim \mathrm{N}$ $(31,9.4)$ change from figure 4 . The distribution of polulation flow is very uneven.

Problem analysis and improvement. Scheduling of No.224 and population flow of its bus station on the weekend is not coordinated. Population flow of the platform is a normal distribution with the passage of time. But scheduling of No.224 bus is a uniform distribution of a straight line. If the bus starts according to the same frequency, when fewer people on the station, it will cause a waste of resources. But when many people are on the station, it cannot meet the needs of passengers.

One bus taking 36 passengers is the best choice to meet the psychological needs of customers according to the investigation. The best scheduling time of bus= average departure interval $\div$ average population flow $\times 36$. According to the Table 1 and Table 2 of the data and the formula above, graphics are shown in Figure 5.

After the improvement, when there are large flows of people, the time of departure interval is properly extended and the frequency of departure is reduced. When there is small flow of people, the interval is shortened and the frequency of departure is improved. This can not only effectively reduce the waste of resources, greatly improve the efficiency of the grid, evenly decreases the customer's waiting time, meet the needs of passengers, and achieve a win-win effect. 


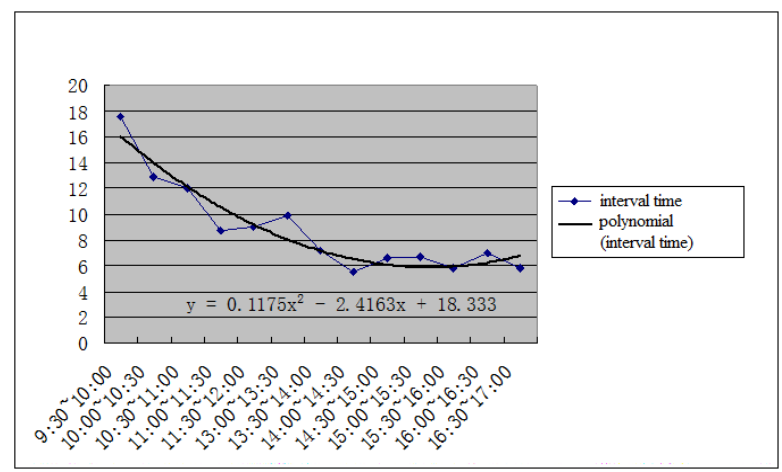

Fig.5 Improved data fitting of departure interval time for No.224

\section{Modeling and Simulation}

The model is established by Flexsim ${ }^{[4-5]}$ is shown in fig.6. The entity mapping control relationship in Flexsim of comprehensive passenger hub system for the Shenyang North Railway Station is studied to optimize the system performance and improve the system efficiency.

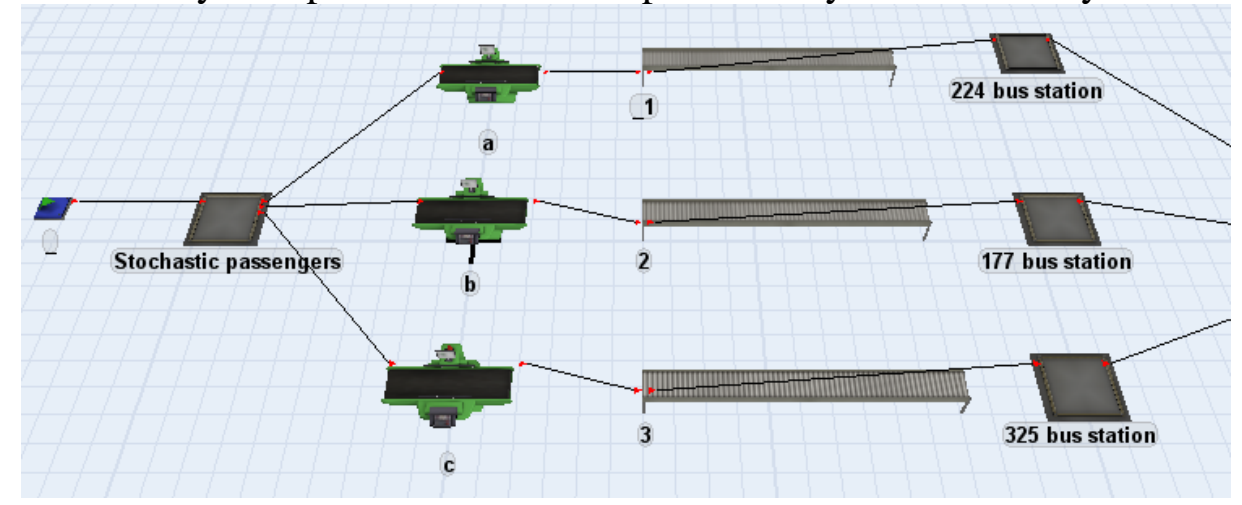

Fig.6 Simulation diagram by Flexsim

\section{Summary}

Simulation model of comprehensive passenger hub system for Shenyang North Railway Station is established according to the scheduling and inventory model combined with different bus scheduling strategy to determine the appropriate grid frequency. The station simulation model by Flexsim is set up, which are to find out the bottleneck of the whole system and formulate adjustment and optimization scheme to achieve both bus corporate profits and passengers' service quality, and provide the basis for transit operator to make departure plans.

\section{References}

[1] Chen Jian, Jin Yan. The application of traffic simulation in comprehensive hub planning, Transportation Enterprise Management,9(2010) 48-49. (in chinese)

[2] Huynh N, Reducing truck turn times at marine terminals with appointment scheduling, Journal of the transportation research board. (2009) 47-57.

[3] Robin Lindsey. Optimal timetables for public transportation, Transportation Research, 43(2001)789-813.

[4] Yu Ge, Lu Jiang, Shi Hongxia, et al. Study on the AGV system within an automatic multi-layered warehouse based on Flexsim, Logistics Technology, 30(2011)75-77.(in chinese)

[5] Li Xuan, Hong Yitian, Zheng Hui, et al. Flexsim system simulation software in the distribution center sorting system design, Logistics Engineering and Management, 31(2009)37-39. (in chinese) 